\title{
Glucose metabolism and gene expression in juvenile zebrafish (Danio rerio) challenged with a high carbohydrate diet: effects of an acute glucose stimulus during late embryonic life
}

\author{
Filipa Rocha ${ }^{1}$, Jorge Dias ${ }^{2}$, Sofia Engrola ${ }^{1}$, Paulo Gavaia ${ }^{1}$, Inge Geurden ${ }^{3}$, Maria Teresa Dinis ${ }^{1}$ \\ and Stephane Panserat ${ }^{3 *}$ \\ ${ }^{1}$ CCMAR, Universidade do Algarve, Campus de Gambelas, 8005-139 Faro, Portugal \\ ${ }^{2}$ SPAROS Lda, Area Empresarial de Marim, Lote C, 8700-221 Olhão, Portugal \\ ${ }^{3}$ INRA, UR1067 Nutrition Metabolism Aquaculture, Pôle d'Hydrobiologie, CD918, F-64310 Saint-Pée-sur-Nivelle, France \\ (Submitted 1 July 2014 - Final revision received 7 October 2014 - Accepted 30 October 2014 - First published online 22 January 2015)
}

\section{Abstract}

Knowledge on the role of early nutritional stimuli as triggers of metabolic pathways in fish is extremely scarce. The objective of the present study was to assess the long-term effects of glucose injection in the yolk (early stimulus) on carbohydrate metabolism and gene regulation in zebrafish juveniles challenged with a high-carbohydrate low-protein (HC) diet. Eggs were microinjected at $1 \mathrm{~d}$ post-fertilisation (dpf) with either glucose $(2 \mathrm{M})$ or saline solutions. Up to $25 \mathrm{dpf}$, fish were fed a low-carbohydrate high-protein (LC) control diet, which was followed by a challenge with the HC diet. Survival and growth of $35 \mathrm{dpf}$ juveniles were not affected by injection or the HC diet. Glucose stimulus induced some long-term metabolic changes in the juveniles, as shown by the altered expression of genes involved in glucose metabolism. On glycolysis, the expression levels of hexokinase 1 (HK1) and phosphofructokinase-6 ( $6 P F K$ ) were up-regulated in the visceral and muscle tissues, respectively, of juveniles exposed to the glucose stimulus, indicating a possible improvement in glucose oxidation. On gluconeogenesis, the inhibition of the expression levels of PEPCK in fish injected with glucose suggested lower production of hepatic glucose. Unexpectedly, fructose-1,6-bisphosphatase $(F B P)$ expression was induced and $6 P F K$ expression reduced by glucose stimulus, leaving the possibility of a specific regulation of the FBP-6PFK metabolic cycle. Glucose metabolism in juveniles was estimated using a $\left[{ }^{14} \mathrm{C}\right]$ glucose tracer; fish previously exposed to the stimulus showed lower retention of $\left[{ }^{14} \mathrm{C}\right] \mathrm{glucose}$ in visceral tissue (but not in muscle tissue) and, accordingly, higher glucose catabolism, in comparison with the saline group. Globally, our data suggest that glucose stimulus at embryo stage has the potential to alter particular steps of glucose metabolism in zebrafish juveniles.

\section{Key words: Carbohydrates: Nutritional programming: Nutrigenomics: Zebrafish}

The ability of fish to use dietary carbohydrates is widely variable among and within species and closely associated with their feeding habits. Fish species that show high dietary protein requirements and, therefore, usually presented as 'carnivorous' fish are generally considered to be poor utilisers of dietary carbohydrates ${ }^{(1-4)}$. In spite of the significant research efforts devoted to this theme, the physiological basis for such apparent glucose intolerance in fish is not fully understood. Despite having the whole enzymatic machinery required for carbohydrate utilisation ${ }^{(3)}$, fish react with a prolonged postprandial hyperglycaemia after the ingestion of carbohydrate-rich diets ${ }^{(1)}$. Various hypotheses have been proposed to explain this poor utilisation of dietary carbohydrates by fish. Insulin deficiency, lack of insulin-dependent GLUT and lack of an inducible hepatic glucokinase have been proven to be false hypotheses ${ }^{(5-8)}$. In contrast, the lower potency of glucose over amino acids as insulin secretagogues; a relatively low number of insulin receptors; the lack of an adequate balance between hepatic glucose uptake (glycolysis) and production (gluconeogenesis); and poor hepatic lipogenesis from glucose have been proven to be valid hypotheses ${ }^{(4,5,9-13)}$. Furthermore, the ubiquitous presence of most key enzymes involved in carbohydrate metabolic pathways among fish species indicate that the poor utilisation may be due to an anomalous hormonal and nutritional regulation caused by evolutionary adaptation ${ }^{(4,14)}$.

The concept of early nutritional programming is being largely studied in mammals to understand how nutritional

Abbreviations: $6 P F K$, phosphofructokinase-6; dpf, days post-fertilisation; $F B P$, fructose-1,6-bisphosphatase; G6Pase, glucose-6-phosphatase; GK, glucokinase; HC, high-carbohydrate low-protein; HK1, hexokinase 1; LC, low-carbohydrate high-protein; PEPCK, phosphoenolpyruvate carboxykinase; $P K$, pyruvate kinase.

*Corresponding author: Dr S. Panserat, fax +33 5595451 52, email panserat@st-pee.inra.fr 
events during critical periods of development can result in persistent physiological changes in adulthood ${ }^{(15)}$. In fish nutrition, this raises the possibility of tailoring specific metabolic pathways or functions in juvenile fish, such as the improvement in the use of dietary carbohydrates as energy substrates $^{(16,17)}$. Glucose, as a simple monosaccharide, is a primary source of energy for cells. Immediately after egg fertilisation, glucose derived from maternal glycogen reserves is the first nutrient to be catabolised for cellular division. However, glycogen stores in fertilised fish eggs are extremely low and rapidly depleted ${ }^{(18,19)}$. Under these circumstances, glucose is not expected to play a pivotal role in nutrientsensing pathways during embryogenesis. However, recent studies have suggested that glucose levels, used as a cofactor, can induce modifications on certain epigenetic mechanisms such as histone acetylation and contribute to genomic imprinting, which, in some cases, can be transgenerational ${ }^{(20,21)}$. Together, these factors support glucose as a suitable nutrient for studying the effectiveness of nutritional programming in fish.

Recently, early zebrafish embryos at $0 \cdot 2 \mathrm{~d}$ post-fertilisation (dpf) were successfully enriched with glucose by means of direct microinjection into the yolk reserves ${ }^{(17)}$. In this previous study, we reported that glucose conditioning had no marked beneficial effects on the ability of juvenile fish to cope with high dietary glucose levels, at least at a molecular level; however, a short-term effect (although transient) related to the early stimulus was observed with the down regulation of several metabolic-related genes. Despite being rather weak effects and based only on molecular data, zebrafish juveniles conditioned by an early glucose stimulus showed some indications of enhanced capacity for glucose storage in the muscle, lower glucose production in the liver and lower glucose transport in the intestinal lumen. However, doubts subsisted whether such effects would be more pronounced if we had exerted the glucose stimulus at a later development stage with fully functional metabolic pathways and with a lower supplemental dose of glucose to avoid a potential overload status and, consequently, cellular damage. Meanwhile, Fang et $a l .{ }^{(16)}$ recently showed that a high dietary carbohydrate stimulus exerted at first feeding stages $(3-5 \mathrm{dpf})$ significantly altered the molecular regulation of carbohydrate utilisation, production, digestion and transport in adult zebrafish.

In this context, the objective of the present study was to explore the effects of glucose injection (nutritional stimulus) in the egg at the late embryo stage of $1 \mathrm{dpf}$ on gene expression of target metabolic pathways and $\left[{ }^{14} \mathrm{C}\right]$ glucose metabolism in juvenile zebrafish challenged with a high-carbohydrate diet. Additionally, the effect of early glucose stimulus on the gene regulation of yolk-sac feeding larvae was also assessed in order to identify possible short-term effects.

\section{Materials and methods}

\section{Microinjection procedure}

Fertilised zebrafish eggs were obtained from natural spawning of wild-type breeding fish (Centre of Marine Sciences). Embryos were injected into the yolk with $4.6 \mathrm{nl}$ of either a saline solution (Danieau) or $2 \mathrm{~m}$-glucose solution, at the late embryo stage of $1 \mathrm{dpf}$ (during the pharyngula period, according to the method described by Kimmel et al. $\left.{ }^{(22)}\right)$. Solutions were prepared according to the procedures described by Rocha et $a l .{ }^{(17)}$. Microinjection was performed using a $0.5 \mathrm{~mm}$-diameter glass capillary inserted on a nanolitre injector (World Precision Instruments) following the same procedures as described by Rocha et $a l .{ }^{(17)}$.

\section{Fish rearing and experimental feeds}

The present experiment was carried out in compliance with the Guidelines of the European Union Council (2010/63/EU) legislation for the use of vertebrate animals ${ }^{(23)}$. After glucose and saline injections (described above), embryos and larvae were raised in triplicate tanks ( $n$ 200) at an initial density of 100 larvae/l, under standardised conditions $\left(28^{\circ} \mathrm{C}\right)$ as described previously by Westerfield ${ }^{(24)}$. An additional group of non-injected embryos was reared simultaneously to monitor egg quality and embryonic development. From $5 \mathrm{dpf}$, larvae were fed Artemia nauplii, which were gradually replaced by an inert diet from 10 to $15 \mathrm{dpf}$. After day 15 , larvae were fed exclusively on a low-carbohydrate highprotein (LC) diet used as the control (Fig. 1). From 25 to
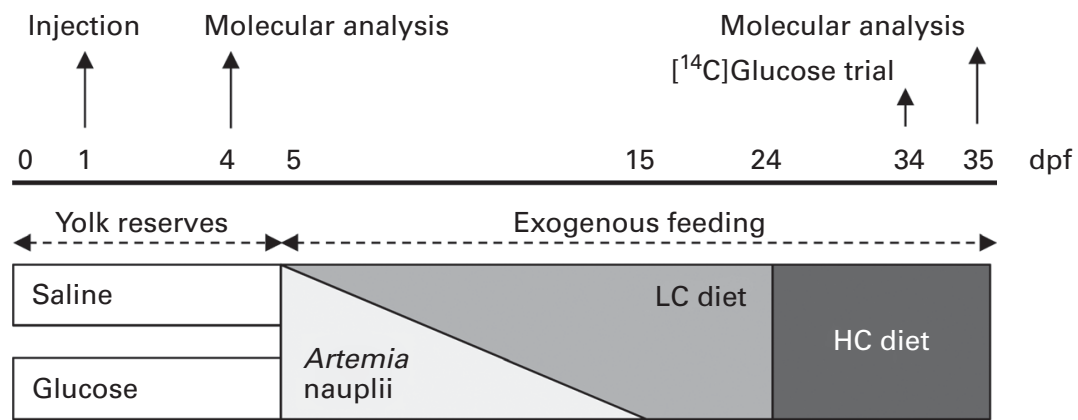

Fig. 1. Experimental set-up for zebrafish rearing and feeding regimen up to $35 \mathrm{~d}$ post-fertilisation (dpf). Embryos were injected into the yolk at $1 \mathrm{dpf}$ either with a saline or $2 \mathrm{M}$-glucose solution. At the beginning of exogenous feeding, larvae were fed with Artemia nauplii, which were gradually replaced by a low-carbohydrate high-protein (LC) control diet. Juveniles were subjected to a $10 \mathrm{~d}$ dietary challenge, being fed exclusively on a high-carbohydrate low-protein (HC) diet. Sampling points for the metabolic trial and gene expression were marked. Age is expressed as dpf at $28^{\circ} \mathrm{C}$. 
$35 \mathrm{dpf}$, all fish from both injection treatments were subjected to a dietary challenge with a high-carbohydrate low-protein (HC) diet (Fig. 1). Throughout the trial, larvae and juvenile zebrafish were fed by hand (four meals/d) until visual satiation. Both diets were well accepted by the fish. Fish mortality was daily monitored, and survival rate was determined at the end of the trial.

Formulation of the experimental diets was based on the use of purified ingredients in order to guarantee a high control of nutritional changes among the diets (Table 1 ). The LC control diet had a high incorporation level of concentrated protein sources (casein, soya isolate, wheat gluten and fish gelatin), guaranteeing a high level of crude protein (70\%) and a low level of carbohydrates (6\%). In the HC (or challenge) diet, the crude protein level was drastically reduced (25\%), whereas carbohydrate level (51\%) was increased through the incorporation of maize dextrin, a highly digestible carbohydrate.

Table 1. Formulation and composition of the low-carbohydrate high-protein (LC) control and the high-carbohydrate low-protein (HC) challenge diets

\begin{tabular}{|c|c|c|}
\hline Diets & LC control & $\mathrm{HC}$ challenge \\
\hline \multicolumn{3}{|l|}{ Ingredients (\%) } \\
\hline Fish gelatin* & $17 \cdot 0$ & $5 \cdot 0$ \\
\hline Caseint & $25 \cdot 0$ & $5 \cdot 0$ \\
\hline Soya protein isolateł & $25 \cdot 0$ & $5 \cdot 0$ \\
\hline Wheat gluten§ & $12 \cdot 8$ & $5 \cdot 0$ \\
\hline Yellow maize dextrin\| & - & $50 \cdot 1$ \\
\hline Fish oilq & $11 \cdot 7$ & $12 \cdot 0$ \\
\hline Vitamin and mineral premix ${ }^{\star \star}$ & $2 \cdot 0$ & $2 \cdot 0$ \\
\hline Monocalcium phosphate†† & $3 \cdot 0$ & 3.5 \\
\hline Guar gum㧊 & $2 \cdot 0$ & $2 \cdot 0$ \\
\hline L-Arg $\ddagger \ddagger$ & - & 1.5 \\
\hline L-Hisłł & - & 0.6 \\
\hline L-lleł‡ & - & 0.5 \\
\hline L- Leuł‡ & - & $2 \cdot 3$ \\
\hline L-Lys $\ddagger \ddagger$ & 1.0 & $2 \cdot 8$ \\
\hline 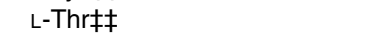 & - & 0.8 \\
\hline L-Trpł‡ & - & 0.2 \\
\hline DL-Metł‡ & 0.5 & 1.2 \\
\hline L-Valł‡ & - & 0.5 \\
\hline \multicolumn{3}{|c|}{ Proximate composition (as-fed basis) } \\
\hline Moisture (\%) & $6 \cdot 32$ & $6 \cdot 57$ \\
\hline Crude protein (\%) & $70 \cdot 12$ & $25 \cdot 32$ \\
\hline Crude fat $(\%)$ & $12 \cdot 34$ & $12 \cdot 23$ \\
\hline Carbohydrates $(\%)^{\S \S}$ & 5.93 & 51.56 \\
\hline Ash (\%) & $5 \cdot 29$ & 4.32 \\
\hline Total P (\%) & $1 \cdot 21$ & 0.98 \\
\hline Gross energy (kJ/g) & $22 \cdot 11$ & $19 \cdot 35$ \\
\hline
\end{tabular}

*Pharma Grade bloom 240: $92 \%$ CP, LAPI Gelatine SPA.

†Edible acid casein 90 mesh: $85 \%$ CP, EPI Ingredients.

¥SEAH Soy Instant: $87 \mathrm{CP} \%$, Seah International.

§VITEN: $86 \%$ CP, $1.3 \%$, Roquette.

II TACKIDEX C070: Roquette.

I Marine oil omega-3: Henry Lamotte Oils $\mathrm{GmbH}$.

${ }^{* *}$ PREMIX Lda. Vitamins (mg/kg diet): DL- $\alpha$-tocopherol acetate, $100 \mathrm{mg}$; sodium menadione bisulphate, $25 \mathrm{mg}$; retinyl acetate, $6.9 \mathrm{mg}$; DL-cholecalciferol, $0.05 \mathrm{mg}$; thiamin, $30 \mathrm{mg}$; riboflavin, $30 \mathrm{mg}$; pyridoxine, $20 \mathrm{mg}$; cyanocobalamin, $0.1 \mathrm{mg}$; nicotinic acid, $200 \mathrm{mg}$; folic acid, $15 \mathrm{mg}$; ascorbic acid, $1000 \mathrm{mg}$; inositol, $500 \mathrm{mg}$; biotin, $3 \mathrm{mg}$; calcium pantothenate, $100 \mathrm{mg}$; choline chloride, $1000 \mathrm{mg}$; betaine, $500 \mathrm{mg}$. Minerals ( $\mathrm{g}$ or $\mathrm{mg} / \mathrm{kg}$ diet): cobalt carbonate, $0.65 \mathrm{mg}$; copper sulphate, $9 \mathrm{mg}$; ferric sulphate, $6 \mathrm{mg}$; potassium iodide, $0.5 \mathrm{mg}$; manganese oxide, $9.6 \mathrm{mg}$; sodium selenite, $0.01 \mathrm{mg}$; zinc sulphate, $7.5 \mathrm{mg} ; \mathrm{NaCl}, 400 \mathrm{mg}$; calcium carbonate, $1.86 \mathrm{~g}$; excipient wheat middlings.

†† Monocalcium phosphate: $22 \% \mathrm{P}, 16 \%$ Ca, Fosfitalia

拉 Sigma-Aldrich Quimica SA.

$\S \S$ Carbohydrate content calculated as: $100-($ moisture + protein + fat + ash).
Both diets were isolipidic (12\%) and dully supplemented with selected crystalline indispensable amino acids and monocalcium phosphate to avoid essential amino acid or phosphorus imbalance. The experimental diets were manufactured by SPAROS Lda. Powder ingredients were grinded (below $100 \mu \mathrm{m}$ ) in a micropulveriser hammer mill (Hosokawa Micron). Powder ingredients and oil sources were then mixed accordingly to the target formulation in a mixer (Sammic BM5E), and the mixture was humidified with $25 \%$ water. The diets were manufactured by temperaturecontrolled extrusion (pellet size $2.0 \mathrm{~mm}$ ) by means of a low-shear extruder (Italplast P55). Upon extrusion, all feed batches were dried in a convection oven (OP 750-UF; LTE Scientifics) for $3 \mathrm{~h}$ at $40^{\circ} \mathrm{C}$. Dry feed pellets were then grinded in a coffee mill and sieved manually to retrieve the desired particle size $(100-200$ and $200-400 \mu \mathrm{m})$. The diets were analysed for proximate composition according to the following procedures: DM after drying at $105^{\circ} \mathrm{C}$ for $24 \mathrm{~h}$; ash content by incineration in a muffle furnace at $500^{\circ} \mathrm{C}$ for $12 \mathrm{~h}$; crude protein $(\mathrm{N} \times 6.25)$ by a flash combustion technique followed by a gas chromatographic separation and thermal conductivity detection (LECO FP428); fat by dichloromethane extraction (Soxhlet); gross energy in an adiabatic bomb calorimeter (IKA C2000); total phosphorus according to the ISO/DIS 6491 method using the vanado-molybdate reagent.

\section{Biological and analytical sampling}

Immediately after injection, samples ( $n$ 30) of glucose- and saline-injected eggs were collected for the analysis of glucose levels by fluorescent spectroscopy using a commercial kit (Amplit Glucose Quantitation Kit; AAT Bioquest). Fluorescence readings were performed in triplicate using a Synergy ${ }^{\mathrm{TM}} 4$ Multi-Mode Microplate Reader controlled by Gen $5^{\mathrm{TM}}$ software (BioTek Instruments). At the end of the experiment ( $35 \mathrm{dpf}$ ), juveniles ( $n 20$ per treatment) were individually sampled for growth determination based on dry weight and total length parameters. Total length was determined using the AxioVision 4.8.2 (Carl Zeiss Limited) program for image analysis, and dry weight measurements were obtained from freeze-dried samples using a precision scale. For gene expression analysis, samples of whole-body larvae ( $n$ 20) from each replicate of glucose- and saline-injected treatments were collected during the endogenous feeding period ( $4 \mathrm{dpf}$ ). At the end of the trial, liver and muscle from individual fish ( $n 6$ per treatment) were sampled $6 \mathrm{~h}$ after feeding for the same purpose. All samples were randomly collected, snap-frozen in liquid $\mathrm{N}_{2}$ and kept at $\left(80^{\circ} \mathrm{C}\right.$ until analysis.

\section{Metabolic trial}

\section{Tube-feeding method}

At $1 \mathrm{~d}$ before the final sampling ( $34 \mathrm{dpf}$ ), juveniles from each treatment ( $n$ 10) were randomly harvested from the tanks and transferred to the flux laboratory for overnight acclimatisation at room temperature $\left(28^{\circ} \mathrm{C}\right)$. Fish were deprived from feed for $16 \mathrm{~h}$ before the metabolic trail. The in vivo method of controlled tube-feeding, as described by Rust et al. ${ }^{(25)}$ and later 
modified by Rønnestad et al. ${ }^{(26)}$, for marine fish was adapted to supply nutrients to freshwater species. This approach was used to assess the effects of both nutritional conditioning (early glucose injection) and increase in dietary carbohydrates on the metabolic handling of glucose by zebrafish juveniles. Following a $16 \mathrm{~h}$ fasting period, zebrafish juveniles were allowed to feed on the HC diet for a period of $40 \mathrm{~min}$. This feeding period was suitable for the uptake of a full meal, as confirmed by observation of the gastrointestinal tract, and within the beginning of the zebrafish gastrointestinal transit ${ }^{(27)}$. Following this single meal, fish were anaesthetised with $33 \mu \mathrm{m}$-tricaine methanesulfonate (Sigma-Aldrich). Subsequently, the radioactive label $\mathrm{D}-\left[{ }^{14} \mathrm{C}(\mathrm{U})\right]$ glucose $(9 \cdot 25 \mathrm{MBq}$; American Radiolabeled Chemicals, Inc.) was added to Ringer salt solution and tube-fed to all fish using a $0 \cdot 19 \mathrm{~mm}$-diameter plastic capillary (Sigma-Aldrich) inserted on a nanolitre injector (World Precision Instruments). Thereafter, three consecutive injections of $4.6 \mathrm{nl}$ were administered into the fish gut. This injection volume $(13.8 \mathrm{nl})$ was in the range of that previously used for marine species in late larval stages ( $>25 \mathrm{~d}$ after hatching): Senegalese sole ${ }^{(28,29)}$; gilthead seabream $^{(30)}$; white seabream ${ }^{(31)}$. After capillary withdrawal, fish were gently rinsed for spillage through two successive wells filled with clean freshwater and transferred into sealed incubation chambers containing $6.5 \mathrm{ml}$ of freshwater. The incubation water was considered to contain all labelled ${ }^{14} \mathrm{C}$ resulting from fish evacuation (evacuated fraction). In addition, an airflow connection was provided between each incubation chamber and a $\mathrm{KOH}$ trap $(5 \mathrm{ml}, 0.5 \mathrm{M})$, in order to collect all ${ }^{14} \mathrm{CO}_{2}$ released by the fish through glucose metabolism (catabolised fraction). After an incubation period of $24 \mathrm{~h}$, juveniles from each injection treatment were sampled individually for muscle and viscera, in order to determine the amount of ${ }^{14} \mathrm{C}$ retained in tissues (retained fraction). Tissue samples were immediately solubilised with Solvable $(500 \mu \mathrm{l}$; PerkinElmer) and kept at $50^{\circ} \mathrm{C}$ for $24 \mathrm{~h}$. Following larval sampling, the incubation chambers were resealed and $1 \mathrm{ml}$ $\mathrm{HCl}(0 \cdot 1 \mathrm{M})$ was added in a series of gradual steps, resulting in a progressive decrease of $\mathrm{pH}$ that causes the rapid diffusion of any remaining ${ }^{14} \mathrm{CO}_{2}$ from the water into the metabolic trap (catabolised fraction) $^{(26)}$. For radioactive counting, dpm were determined in all samples by adding the Ultima Gold XR scintillation cocktail (PerkinElmer) and counting in a TriCarb 2910TR Low Activity Liquid Scintillation analyser (PerkinElmer). Metabolic budgets were calculated after subtracting blanks of each fraction (evacuated, catabolised and retained). Results for each fraction are expressed as a percentage of total label tube-fed, i.e. the sum of $\mathrm{dpm}$ in all the compartments of the metabolic chamber and fish.

\section{Gene expression analysis}

\section{Real-time PCR}

Analyses of mRNA levels were performed at two distinctive periods and sample types: at $4 \mathrm{dpf}$ in whole-body larvae, for assessing the short-term effect of early glucose stimulus (injection), and at $35 \mathrm{dpf}$ in the visceral and muscle tissues of juveniles, for assessing the effects of both early glucose stimulus and dietary challenge. Juvenile fish were sampled $6 \mathrm{~h}$ after the last meal, based on previous data identifying this period as relevant for examining the postprandial response of genes in zebrafish ${ }^{(32,33)}$. Total RNA was extracted from all samples using $1 \mathrm{ml} \mathrm{TRIzol}{ }^{\circledR}$ reagent (Invitrogen). From the resulting total RNA, $1 \mu \mathrm{g}$ was reverse transcribed into complementary DNA using the SuperScript III RNase H Reverse Transcriptase Kit (Invitrogen) with random primers (Promega). Molecular analysis was focused on the expression of target genes related to glycolysis ( $G K$, glucokinase; $H K 1$, hexokinase 1; $6 P F K$, phosphofructokinase-6; $P K-L, P K-M$, pyruvate kinase, both liver and muscle isoforms), gluconeogenesis (PEPCK, phosphoenolpyruvate carboxykinase, both cytosolic and mitochondrial isoforms; $F B P$, fructose-1,6bisphosphatase; G6Pase, glucose-6-phosphatase), lipogenesis (FAS, fatty acid synthase; G6PDH, glucose-6-phosphate dehydrogenase; $M E c$, cytosolic malic enzyme) and glycogen metabolism ( $G S$, glycogen synthase; GP, glycogen phosphorylase). These primers were considered as good molecular markers for nutritional studies in zebrafish ${ }^{(17,33)}$. Gene expression levels were determined by quantitative real-time RT-PCR performed by means of the iCycler iQ (Bio-Rad). Analyses were performed on $5 \mu$ l of diluted complementary DNA using the $\mathrm{iQ} \mathrm{SYBR}^{\circledR}$ Green supermix in a total PCR volume of $15 \mu \mathrm{l}$ containing, $200 \mathrm{~nm}$ of each primer. Thermal cycling was initiated with the incubation at $95^{\circ} \mathrm{C}$ for $90 \mathrm{~s}$ for Taq DNA polymerase activation, then thirty-five steps of PCR were performed, each one consisting of heating at $95^{\circ} \mathrm{C}$ for $20 \mathrm{~s}$ for denaturing and at $55^{\circ} \mathrm{C}$ or $62^{\circ} \mathrm{C}$ for $30 \mathrm{~s}$ for annealing and extension, depending on the primers. After the final cycle of the PCR, melting curves were systematically monitored $\left(55^{\circ} \mathrm{C}\right.$ temperature gradient at $0.5^{\circ} \mathrm{C} / \mathrm{s}$ from 55 to $\left.94^{\circ} \mathrm{C}\right)$. Each quantitative PCR run included duplicates of samples (reverse transcription) and negative controls (samples without RT or mRNA or complementary DNA). Target gene expression analysis of whole-body larvae and visceral tissue from juveniles was performed using elongation factor-1 $(E F 1 \alpha)$ as the reference gene, while $18 S$ rRNA was used as the reference gene for muscle samples, once $E F 1 \alpha$ was not being stably expressed in this tissue. Both EF1 $\alpha$ and $18 S$ were employed as non-regulated reference genes and their gene expression values did not significantly change over the respective time frame or tissue type ${ }^{(34)}$ (data not shown). Relative quantification of gene expression was performed using the mathematical model described by Pfaffl $^{(35)}$.

\section{Statistical analysis}

Data are presented as means with their standard errors of the mean. Criteria expressed as a percentage were arcsine transformed previously to the statistical analysis. The effects of glucose injection on the several analysed parameters in larvae and juvenile fish were tested using SPSS $^{\circledR}$ statistics software 16.0 for Windows by means of an unpaired twotailed Student's $t$ test. Differences were considered significant at $P<0.05$. For relative quantification of gene expression in juvenile fish, the control group was set as the saline-injected HC diet-fed group. 
Table 2. Survival $(n 3)$ and growth ( $n$ 20) of zebrafish juveniles initially injected with a saline or glucose solution and challenged with a high-carbohydrate low-protein diet ${ }^{\star}$

(Mean values with their standard errors)

\begin{tabular}{|c|c|c|c|c|}
\hline & \multicolumn{2}{|c|}{ Saline } & \multicolumn{2}{|c|}{ Glucose } \\
\hline & Mean & SEM & Mean & SEM \\
\hline Survival (\%) & 68.0 & $6 \cdot 1$ & $61 \cdot 1$ & 5.8 \\
\hline TL (mm/fish) & $11 \cdot 1$ & 0.5 & $10 \cdot 0$ & 0.5 \\
\hline TL variation coefficient (\%) & 21.7 & & 21.4 & \\
\hline Dry weight (mg/fish) & 4.8 & 0.7 & 4.7 & 0.6 \\
\hline
\end{tabular}

$\mathrm{TL}$, total length.

*Student's $t$ test.

\section{Results}

\section{Glucose supplementation, growth performance and} survival rate

In comparison with eggs of the saline treatment, those microinjected with a $2 \mathrm{M}$-glucose solution $(9.2 \mathrm{nmol} / \mathrm{egg})$ showed a 6 -fold increase in glucose levels. No permanent damage on egg chorion or signs of leakage through the puncture hole was recorded after the injection. Zebrafish growth and survival was affected neither by early glucose stimulus nor by the dietary challenge with high carbohydrates $(P>0 \cdot 05)$. At the end of the experiment, juveniles showed similar mean values for dry weight (4.7-4.8 mg) and total length (10.0-11.1 mm) (Table 2). The survival rate varied between 61 and $68 \%$ and values were within the expected range for zebrafish fed with live feed and purified diets. Carvalho et al. ${ }^{(36)}$ showed that $27-\mathrm{d}-$ old zebrafish fed from mouth-opening with a semi-purified diet reached a good growth $(7 \cdot 0(\mathrm{SD} 0.2) \mathrm{mm})$ and survival (55\%) rate.

\section{Effects of early glucose stimulus on $\left[{ }^{14} \mathrm{C}\right]$ glucose} metabolism in fish fed with carbohydrates

The survival rate of zebrafish after $24 \mathrm{~h}$ of incubation in metabolic chambers was 89 and $100 \%$ for the glucose- and saline-injected treatments, respectively. The results showed that in juvenile fish, glucose evacuation and absorption was not significantly affected by early glucose conditioning

(a)

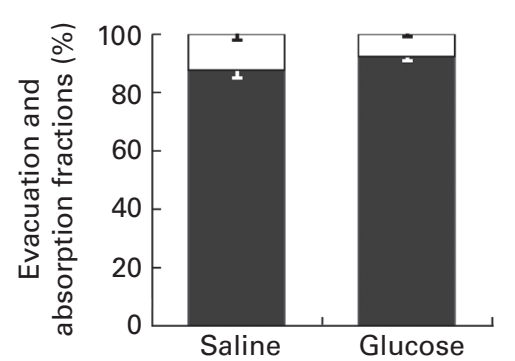

( $P>0.05$; Fig. 2(a)). Zebrafish presented high levels of glucose absorption (over 87\%) under the same intake amount of carbohydrates. Juveniles subjected to the early glucose stimulus showed significantly lower $(P<0.05)$ retention of glucose in visceral tissue (but not in muscle tissue) and, consequently, higher glucose catabolism $(P=0.072)$ in comparison with the saline-injected group. Retention efficiency in visceral tissue was significantly reduced in juveniles injected with glucose compared with the saline-injected group (6.0 and $11.5 \%$, respectively; Fig. 2(b)).

Although no significant differences were found, glucose catabolism showed a trend towards an increase in the glucose-injected fish rather than in the saline-injected fish (75.8 and $68 \%$, respectively) (Fig. 2(b)).

\section{Effects of early glucose stimulus on metabolic gene expression in yolk-sac larvae}

The RNA levels of enzymes involved in the intermediary metabolism of yolk-sac larvae ( $4 \mathrm{dpf}$ ) were compared between the saline- and glucose-injected groups (Table 3). For the majority of the analysed genes, mRNA levels remained unaltered between the saline- and glucose-injected treatments. Only the $P K$ gene (muscle isoform) was significantly upregulated in glucose-injected larvae $(P<0.05$; Table 3$)$, while the $M E c$ gene showed a slight but not significant decrease in its expression $(P=0.056)$. These results suggest that the glucose stimulus had no marked effects on gene regulation in 4 dpf larvae.

\section{Effects of early glucose stimulus on metabolic gene expression in fish fed with carbohydrates}

The same set of target genes was analysed in two tissue types of juvenile fish $(35 \mathrm{dpf})$ : viscera and muscle. The long-term effects on gene expression in fish injected with glucose at an early embryo stage and later subjected to a feeding challenge with high carbohydrates are given in Table 3.

In viscera, the gene expression of $G K$ was unaltered regardless of the injection treatment (glucose stimulus). In contrast, the expression of $H K 1$ was significantly up-regulated

(b)

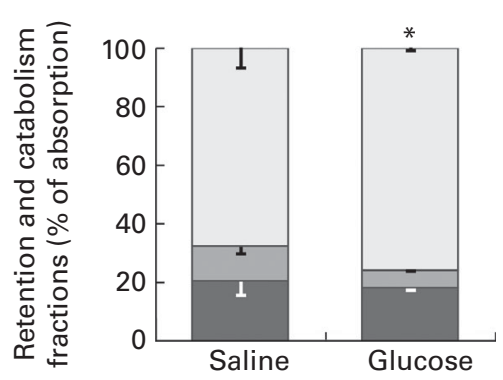

Fig. 2. Study of glucose metabolism in zebrafish juveniles. (a) Percentage of the absorbed (black bar) and evacuated (white bar) $\left[{ }^{14} \mathrm{C}\right] \mathrm{glucose}$ in tube-fed zebrafish juveniles initially subjected to either a saline or glucose injection (stimulus) and fed a high-carbohydrate low-protein ( $\mathrm{HC}$ ) diet. (b) Percentage of $\left[{ }^{14} \mathrm{C}\right] \mathrm{glucose}$ retained in muscle tissue (dark-grey bar) and visceral tissue (medium-grey bar), and percentage of $\left[{ }^{14} \mathrm{C}\right]$ glucose catabolised (light-grey bar) in tube-fed zebrafish juveniles initially subjected to either a saline or glucose injection (stimulus) and fed a HC diet. Retention and catabolism fractions are associated with the absorbed label in the fish. Values (absorption, evacuation, retention and catabolism) are means, with their standard errors represented by vertical bars ( $n$ 10). ${ }^{*}$ Mean value was significantly different from that of the saline-injected group $(P<0.05$; Student's $t$ test). 
Table 3. Relative expression of metabolic genes involved in glycolysis (A), gluconeogenesis (B) lipogenesis (C) and glycogen metabolism (D) in whole-body larvae (4d post-fertilisation (dpf)) and visceral and muscle tissues from zebrafish juveniles ( $35 \mathrm{dpf}$ ), initially injected with a saline (control) or glucose (stimulus) solution and challenged with a high-carbohydrate low-protein diet* (Mean values with their standard errors; $n 6$ )

\begin{tabular}{|c|c|c|c|c|c|c|}
\hline \multirow[b]{2}{*}{ Pathways } & \multirow[b]{2}{*}{ Gene } & \multicolumn{2}{|c|}{ Saline injection } & \multicolumn{2}{|c|}{ Glucose injection } & \multirow[b]{2}{*}{$P$} \\
\hline & & Mean & SEM & Mean & SEM & \\
\hline \multicolumn{7}{|c|}{ Whole-body larvae ( $4 \mathrm{dpf})$} \\
\hline A & GK & $1 \cdot 1$ & 0.23 & 1.5 & 0.32 & 0.351 \\
\hline A & $H K 1$ & 1.0 & 0.09 & 0.9 & 0.04 & 0.280 \\
\hline A & 6PFK & 1.0 & 0.16 & 0.7 & 0.04 & 0.094 \\
\hline A & $P K-L$ & 1.8 & 0.14 & 1.8 & 0.12 & 0.955 \\
\hline A & PK-M & 1.0 & 0.05 & 1.2 & 0.06 & 0.038 \\
\hline B & PEPCKC & 1.0 & 0.09 & 0.9 & 0.07 & 0.290 \\
\hline B & PEPCKm & 1.0 & $0 \cdot 10$ & 0.8 & 0.02 & 0.159 \\
\hline B & $F B P$ & 1.0 & 0.03 & $1 \cdot 0$ & 0.08 & 0.979 \\
\hline B & G6Pase & 1.0 & 0.13 & 0.8 & 0.07 & 0.138 \\
\hline C & FAS & $1 \cdot 1$ & 0.19 & 0.9 & 0.07 & 0.333 \\
\hline C & G6PDH & 1.0 & 0.14 & 0.9 & 0.04 & 0.250 \\
\hline C & $M E c$ & 1.0 & 0.03 & 0.8 & 0.07 & 0.056 \\
\hline D & GS & 1.0 & 0.04 & $1 \cdot 1$ & 0.06 & 0.111 \\
\hline D & GP & 1.0 & 0.03 & 1.0 & 0.07 & 0.936 \\
\hline \multicolumn{7}{|c|}{ Viscera tissue ( $35 \mathrm{dpf}$ ) } \\
\hline A & GK & $1 \cdot 1$ & 0.18 & 0.9 & 0.24 & 0.657 \\
\hline A & $H K 1$ & 1.0 & 0.16 & 2.5 & 0.58 & 0.040 \\
\hline A & 6PFK & 1.0 & 0.08 & 0.7 & 0.06 & 0.009 \\
\hline A & $P K-L$ & 1.0 & 0.10 & 0.8 & 0.14 & 0.219 \\
\hline B & PEPCKC & 1.0 & 0.05 & 0.5 & 0.06 & 0.000 \\
\hline B & PEPCKm & 1.0 & 0.06 & 0.6 & 0.07 & 0.002 \\
\hline B & $F B P$ & $1 \cdot 1$ & 0.24 & 39.5 & $12 \cdot 28$ & 0.034 \\
\hline B & G6Pase & 1.0 & 0.11 & 0.8 & 0.06 & 0.171 \\
\hline C & FAS & $1 \cdot 3$ & 0.36 & 1.9 & 0.37 & 0.292 \\
\hline C & G6PDH & $1 \cdot 1$ & 0.11 & 1.0 & 0.15 & 0.830 \\
\hline C & $M E c$ & $1 \cdot 1$ & 0.25 & 0.9 & 0.11 & 0.374 \\
\hline D & GS & $1 \cdot 1$ & 0.24 & 1.6 & 0.38 & 0.291 \\
\hline D & GP & $1 \cdot 1$ & 0.15 & 1.3 & 0.20 & 0.424 \\
\hline \multicolumn{7}{|c|}{ Muscle tissue ( $35 \mathrm{dpf}$ ) } \\
\hline A & $H K 1$ & $1 \cdot 1$ & 0.19 & 0.9 & 0.15 & 0.537 \\
\hline A & 6PFK & 1.0 & 0.15 & 1.6 & 0.18 & 0.048 \\
\hline$A$ & $P K-M$ & 1.0 & 0.10 & 0.7 & 0.06 & 0.055 \\
\hline B & GS & 1.0 & 0.08 & 0.9 & 0.08 & 0.315 \\
\hline B & $G P$ & 1.8 & 1.02 & 0.4 & 0.09 & 0.252 \\
\hline
\end{tabular}

* Expression values of larvae and visceral tissue were normalised with $\alpha$-elongation factor 1 transcripts $(E F 1 \alpha)$, while that of muscle tissue was normalised with $18 \mathrm{~S}$ transcripts. Relative fold differences between the treatments were analysed by Student's $t$ test $(P<0.05)$. Age is expressed as dpf at $28^{\circ} \mathrm{C}$. For a description of the gene symbols, refer to the 'Gene expression analysis' section.

$(P=0.04)$, while that of $6 P F K$ was down-regulated $(P=0.009)$ in glucose-injected fish, in comparison with the control group (saline-injected). Also, the transcript levels of $P K-L$ were not affected by the early glucose stimulus in the long term. On the gluconeogenic pathway, the expression levels of PEPCKC and PEPCKm were inhibited in glucose-injected fish ( $P=0.000$ and $P=0.002$, respectively), while that of the G6Pase gene was not affected in the long term. Surprisingly, the gene expression level of $F B P$ was reverse-regulated as expected for this pathway: juveniles that were exposed to the glucose stimulus showed higher levels of expression than the saline group $(P=0.034)$. For genes involved in lipogenesis and energy production (FAS, G6PDH and $M E C$ ), no long-term effects related to the glucose stimulus were found (Table 3). Similar observations were found for GS and GP genes responsible for glycogen metabolism (Table 3).

In the muscle tissue of juvenile fish, only the gene expression level of $6 P F K$ was found to be significantly up-regulated ( $P=0 \cdot 038)$ by early glucose injection (Table 3 ). Therefore, glucose injection increased the expression of $6 P F K$ in juvenile fish, whereas genes encoding for glycolysis (HK1 and $P K-M$ ) and glycogen metabolism (GS and GP) were not affected, in the long term, by early glucose conditioning (Table 3).

\section{Discussion}

Fish nutritionists struggle to establish balanced formulations where large amounts of plant ingredients could be included without compromising the nutritional requirements and a good acceptance of the diet by the fish ${ }^{(37)}$. The inclusion of plant ingredients, be it dietary protein or starch sources, enhances the overall intake of carbohydrates. However, the ability of fish to use dietary carbohydrates as an energyyielding substrate is widely variable among species with different feeding habits. New trends in the field of fish 
nutrition begin to emerge, such as the concept of early nutritional programming, as a promising strategy to enhance the use of alternative feedstuffs ${ }^{(38,39)}$. We believe that such an approach has the potential to improve specific metabolic pathways, through actions during embryonic development that could permanently alter the capacity of adult fish to cope with dietary sources rich in carbohydrates. However, studies in mammals have shown that the period in which the programming stimulus occurs is usually confined to early stages (pre- or postnatal) that influence the 'imprinting' effect as well as the long-lasting outcomes in adulthood ${ }^{(40,41)}$. The goal of the present study was to gain further knowledge on the effects of a hyperglucidic stimulus during the final stage of fish embryogenesis on growth, nutrient metabolism and gene expression regulation in zebrafish juveniles subjected to a drastic increase in the ratio of dietary carbohydrates:proteins.

\section{Effects of early glucose stimulus on the growth and survival of zebrafish}

In our previous study, the glucose injection used as a trigger for nutritional programming in zebrafish eggs $(0 \cdot 2 \mathrm{dpf})$ was found to suppress in the embryos ( $4 \mathrm{dpf}$ ) the transcription level of several genes involved in glycolysis, glucose transport and lipogenesis ${ }^{(17)}$. The inhibition of these metabolic pathways was somehow unexpected since the reverse (stimulation) was observed in several fish species and at later life stages, after the intake of high dietary carbohydrates ${ }^{(4)}$. We, therefore, considered the possibility that glucose overload at this incipient developmental stage induced cellular damages or compromised key metabolic regulators. Here we explore a new 'metabolic window' for glucose delivery (stimulus) at a later period of embryonic development $(1 \mathrm{dpf})$. This period was selected based on two important features: the level of endogenous glucose in the yolk and the stage of embryo development. Zebrafish dynamically regulates glucose during embryogenesis, reaching the highest endogenous levels at $1 \mathrm{dpf}$, before hatching $^{(17,42,43)}$. We hypothesised that supplementation with high doses of glucose $(9.2 \mathrm{nmol} / \mathrm{egg})$ while endogenous glucose levels are elevated would contribute to a better adaptation of embryos for hyperglycaemia conditions. A lower dose may mask the stimulus effect by not altering enough the ratio of carbohydrate over other macronutrients, taking into account the overall low glucose level in cyprinid eggs ${ }^{(44)}$. The glucose injections $(9.2 \mathrm{nmol} / \mathrm{egg})$ increased by 6 -fold the glucose levels relative to those in $1 \mathrm{dpf}$ embryos of the salineinjected group (control). In absolute levels, the amount of glucose injected into the egg was similar to basal glycaemia levels found in adult zebrafish fasted for $24 \mathrm{~h}$ (about $2.5 \mathrm{~mm}$; $40-45 \mathrm{mg} / \mathrm{l})^{(45)}$. Thus, the achieved glucose supplementation can be considered within the physiological range for this species. At the $1 \mathrm{dpf}$ stage, major processes of organogenesis are ongoing in several systems, such as the emergence of hepatic and pancreatic buds (future key metabolic organs) ${ }^{(46,47)}$, the functioning of the heart and circulatory system and the appearance of muscle spontaneous contractions ${ }^{(22,48)}$. In addition, the transcriptional regulation of the insulin gene and the gluconeogenic genes fructose-bisphosphate aldolase and phosphoenolpyruvate carboxykinase already occurs at this early stage ${ }^{(42,49)}$. Therefore, the stage of $1 \mathrm{dpf}$ can be considered of high genetic plasticity, once important metabolic pathways are newly established or in the process of becoming active, suggesting that possible epigenetic alterations can occur during this period due to early nutritional events ${ }^{(50)}$.

To avoid the influence of sexual dimorphism on hepatic gene transcription already reported in zebrafish ${ }^{(51)}$, the present trial was conducted up to $35 \mathrm{dpf}$ ( 5 weeks) so that fish could remain immature. Evidence on the proteomic field had demonstrated that zebrafish can mature before reaching 3 months (90 dpf), in few cases from $30 \mathrm{dpf}$ onwards ${ }^{(52)}$, suggesting that fish length (growth) can have a stronger effect on sexual maturation rather than age ${ }^{(53)}$. We found that glucose supplementation by microinjection did not impair embryonic development, and that the stimulus along with a drastic increase in carbohydrate intake had no detrimental effects on the growth and survival of juvenile fish. The lack of the negative effects on physiological parameters is in conformity with other nutritional programming studies performed in fish ${ }^{(16,17,38)}$.

Immediate and persistent effects of early glucose stimulus on gene expression and metabolic utilisation of glucose in juvenile fish

In mammals, prenatal exposure to high glucose levels can permanently alter adult metabolism and trigger diet-related diseases such as diabetes, the metabolic syndrome and obesity ${ }^{(54)}$. Despite the lack of full knowledge on the mechanisms involved in metabolic regulation by nutritional factors, there is strong evidence that the genome can be 'imprinted' to store the memory of the early nutritional event ${ }^{(15)}$. However, caution should be taken in extrapolating the programming concept from mammals to fish. Mammals and fish exhibit very distinct embryonic development (in uterus $v$. ex uterus); thus, stimulus delivery during a sensitive phase becomes more restricted to the control and manipulation of fish, mostly because fish embryos operate as energetically closed systems during yolk reserve consumption ${ }^{(19)}$. Furthermore, fish have a poor control over glucose homeostasis and exhibit slow metabolic rates for glucose utilisation compared with mammals ${ }^{(2)}$. Therefore, the results from the present study addressing metabolic programming by early glucose stimulus will be cautiously discussed in comparison with mammals, whenever possible.

Short-term effect of early glucose stimulus on metabolic gene expression. The short-term effect related to glucose injection (stimulus) on the gene expression of free-swimming $4 \mathrm{dpf}$ larvae that still rely exclusively on endogenous yolk reserves for nutrient supply was assessed. From the metabolic genes analysed, only the expression level of $P K$ (muscle isoform) was up-regulated in the glucose-injected group. In mammals, the expression of $P K$ is regulated by both dietary carbohydrates and hormones (insulin and glucagon) at a pre- and post-translational level ${ }^{(55)}$. Such dynamic regulation is thought to occur in adult zebrafish according to different feeding conditions: refeeding a commercial diet poorly 
regulates the postprandial expression of $P K$, while a high carbohydrate meal induces its expression ${ }^{(33)}$, with the latter being in line with the higher $P K$ mRNA levels after the delivery of the glucose stimulus at $4 \mathrm{dpf}$. Overall, the early glucose stimulus had a poor short-term effect on the transcript levels of zebrafish larvae, which may be due to the $3 \mathrm{~d}$ gap between glucose injection (at $1 \mathrm{dpf}$ ) and sampling (at $4 \mathrm{dpf}$ ). However, this does not exclude the possibility of a long-term effect of glucose injection at a later life stage, when the fish are confronted again to a challenging nutritional condition. Indeed, sea bass larvae fed diets containing different highly unsaturated fatty acid levels showed no change in the expression levels of several lipogenic enzymes during the first days of stimulus, whereas long-term molecular changes were found in juvenile fish fed a highly unsaturated fatty acid-deficient diet $^{(39)}$. In terms of short-term effects, we obtained less responsiveness of metabolic genes towards glucose stimulus delivered at $1 \mathrm{dpf}$ in comparison with our previous study, where glucose was injected at $0.2 \mathrm{dpf}^{(17)}$. Although the glucose stimulus was the same in both studies $(9 \cdot 2 \mathrm{nmol} / \mathrm{egg})$, the shift of stimulus delivery towards a 'window' of high embryonic development ( $1 \mathrm{dpf}$ ) did not inhibit gene expression, which allowed excluding the hypothesis of cell damage due to glucose overload.

Long-term effect of early glucose stimulus on metabolic gene expression. The long-term effect was evaluated in juvenile fish ( $35 \mathrm{dpf}$ ) after being challenged for $10 \mathrm{~d}$ with the HC diet, with the idea that the early glucose injection may generate a 'metabolic memory' for improving the future use of carbohydrates. The present study confirms the potential of a single glucose injection (at $1 \mathrm{dpf}$ ) to induce persistent molecular changes, as shown by the enhanced expression of genes involved in the first step of glycolysis and gluconeogenesis pathways in the visceral tissue of juveniles conditioned by the glucose stimulus. The increase in the expression level of $H K 1$ and the simultaneous decrease in the expression of PEPCK suggest a higher capacity for glucose phosphorylation as well as a lower glucose production, and thus, the possibility of glucose stimulus to 'programme' these two major pathways towards a more efficient control of glucose homeostasis when subjected again to hyperglycaemic conditions. Although not fully understood, the persistent hyperglycaemia observed in several fish species after high carbohydrate intakes has been ascribed to an atypical regulation of hepatic gluconeogenesis ${ }^{(56,57)}$. More specifically, in contrast to mammals, fish transcriptional regulation of gluconeogenic genes does not seem to be down-regulated by high dietary carbohydrate intakes ${ }^{(12,57-59)}$. As such, the possibility to programme and decrease this pathway in conditions of hyperglycaemia (through an early glucose stimulus) is encouraging. Here we found that both mitochondrial and cytosolic isoforms of the PEPCK gene were affected by the stimulus at the late juvenile stage. A similar down-regulation of PEPCKC was also reported in zebrafish juveniles from our previous study following glucose injections at $0 \cdot 2 \mathrm{dpf}^{(17)}$, which reinforces our hypothesis of early nutritional programming. Also, the expression of the glycolytic HK1 gene, known to be poorly regulated by dietary carbohydrates in fish ${ }^{(60,61)}$ but found here to be enhanced by the early stimulus, appears as a relevant indication for the occurrence of genomic imprinting. Furthermore, the beneficial effects of glucose injection at $1 \mathrm{dpf}$ upon HK1 regulation contrast with our data obtained after glucose injection at $0 \cdot 2 \mathrm{dpf}$, where HK1 was down-regulated ${ }^{(17)}$. The analysis of HK1 enzyme activity in viscera is, however, needed to confirm the physiological relevance. A recent study on metabolic programming of adult zebrafish, but exerting the nutritional stimulus at the larval first-feeding stage showed the same molecular pattern of glycolysis stimulation and gluconeogenesis inhibition following early high carbohydrate intakes ${ }^{(16)}$. In contrast, the gene expression of $G K$ that is highly responsive in fish to rises in dietary carbohydrate intake $\mathrm{f}^{(7,33,60,62,63)}$ was not persistently affected by the glucose stimulus, which is in line with our previous data ${ }^{(17)}$. The lack of programming effects for the $G K$ gene could be related to the lower sensitivity of the GK enzyme to punctual hyperglucidic stimuli delivered during early stages of fish development, as observed in zebrafish and rainbow trout ${ }^{(16,38)}$.

On the downstream reactions of both pathways, the longterm effect of glucose stimulus on the expression of $6 P F K$ (key glycolytic enzyme) and FBP (the opposing gluconeogenic enzyme) genes was unexpected. Results in viscera demonstrated that both genes were regulated in the reverse way of what was anticipated: the glycolytic flux was reduced (6PFK down-regulated), whereas gluconeogenesis was increased ( $F B P$ up-regulated). Given the similarities between fish and mammals on this enzyme-substrate cycle, the programming effect of glucose stimulus on these genes could have been masked by other factors such as hormonal or allosteric control $^{(3,58)}$. However, the expression of $6 P F K$ was regulated differently according to tissue type: being downregulated in viscera but up-regulated in the muscle by the glucose injection. In addition, it was the only gene to be positively altered in muscle tissue, as a long-term consequence of the glucose stimulus. So far, these results present the first indication that the 6PFK-FBP loop can be a target of nutritional programming by early glucose stimulus; however, the reason why the 'memory' stored at the genome after the stimulus resulted in such an unexpected programming of 6PFK-FBP remains unclear. Finally, the last step of both metabolic pathways regulated by PK (glycolysis) and G6Pase (gluconeogenesis) enzymes was not affected at a molecular level by early glucose injection, suggesting that the stimulus was not suitable for a permanent imprinting of these genes. For the $P K$ gene, the short-term induction recorded at $4 \mathrm{dpf}$ might indicate that some short-term effects related to the stimulus can be reversible at later stages of development. Likewise, previous studies showed no long-term effects of early glucidic stimuli on G6Pase and PK mRNA levels in juvenile rainbow trout and zebrafish ${ }^{(16,17,38)}$. However, it has been shown that $P K$ gene expression can be up-regulated by the increase in dietary carbohydrates, as in mammals ${ }^{(33,55,64)}$, in contrast to G6Pase which, depending on fish species, appears to be poorly or even not regulated ${ }^{(12,62,65,66)}$. Therefore, the regulation of a certain metabolic gene in response to higher carbohydrate intake cannot be used as an indicator of possible long-term effects related to early glucidic stimulus. 
The different susceptibilities of each gene to epigenetic modifications as well as all the different epigenetic mechanisms that can be involved after an early nutritional event are important factors to be considered for possible programming effects $^{(50,67)}$

Concerning the genes involved in lipogenesis and glycogen metabolism, the early glucose stimulus had no long-term effects as all the analysed genes had the same level of expression between the saline- and glucose-injected fish. This result with respect to lipogenesis is in line with our earlier data on zebrafish conditioned to glucose at $0 \cdot 2 \mathrm{dpf}^{(17)}$, but disagrees with the hypothesis of increased lipogenesis as a consequence of the early glucose stimulus as anticipated from feeding studies with fish using high dietary carbohydrates $^{(64,68)}$. Studies on the time course of adaptation of lipogenic enzymes in coho salmon revealed that at least $2-3$ weeks are required to cause changes in the activities of these enzymes in response to dietary changes ${ }^{(69)}$. For lipogenesis, our sampling after $10 \mathrm{~d}$ of HC dietary challenge may, therefore, not represent metabolically steady-state conditions fully under the influence of the nutritional history of the glucose stimulus. In contrast, since the stimulus did not improve glycogenesis (glucose storage in muscle), as occurred previously in zebrafish ${ }^{(17)}$, one could consider that glycogen synthesis may have been affected by the reduced amino acid levels in the HC diet. Knowing that amino acids are potent insulin secretagogues in mammals ${ }^{(70)}$ as in fish ${ }^{(9,11)}$, glycogen metabolism could be regulated in a way similar to that in mammals. In this way, the drastic reduction in protein level towards carbohydrate incorporation in the HC challenge diet and the subsequent lowering of amino acids may have limited the full potential of glucose stimulus to program glycogen metabolism in juvenile zebrafish.

Long-term effect of early glucose stimulus on glucose use. The metabolic fate of the tube-fed $\left[{ }^{14} \mathrm{C}\right]$ glucose tracer revealed that juvenile zebrafish can achieve high absorption levels (over $87 \%$ ) of dietary glucose for subsequent retention in tissues or catabolism, regardless of the early nutritional history. Juveniles that were exposed to the glucose stimulus had significantly lower $\left[{ }^{14} \mathrm{C}\right]$ glucose retention in visceral tissue and, accordingly, higher catabolism, in comparison with the saline-injected group, suggesting an enhancement of glucose oxidation and even a possible decrease in glycogen storage. However, given that no further analysis on glycogen or lipid content in tissues was performed, our hypotheses concerning $\left[{ }^{14} \mathrm{C}\right]$ glucose retention in tissues are limited. Nevertheless, these results agree with those observed at a molecular level, as fish injected with glucose showed an up-regulation of the expression of $H K 1$ (viscera) and $6 P F K$ (muscle) genes involved in glucose oxidation. Clearly, glucose is an important substrate for oxidation in zebrafish; however, its metabolic utilisation can be enhanced by means of early programming, as demonstrated herein. Such an approach raises the possibility of even greater results upon carnivorous species with less capacity to use dietary carbohydrates as an energy source.

\section{Conclusion}

We demonstrated that the late embryo stage is a period of high genetic plasticity and better suitable for nutritional stimulus delivery in zebrafish, when compared with incipient stages of $0.2 \mathrm{dpf}$. Our data suggest that, at least at a molecular level, the two major pathways for glucose metabolism were permanently modified by early glucose stimulus at specific key metabolic steps. Although few genes were modified by the early stimulus, juvenile fish fed high carbohydrates showed an improved capacity for glucose phosphorylation and lower glucose production in viscera. The metabolic fate of dietary carbohydrates showed that the early glucose injection lowered the retention of $\left[{ }^{14} \mathrm{C}\right]$ glucose in visceral tissue, thereby promoting higher catabolism by oxidative processes. The present study contributes to the generation of new knowledge on nutritional programming on fish following glucose injection during embryogenesis.

\section{Acknowledgements}

The authors acknowledge the EDGE group (Centre of Marine Sciences) for gently conceding zebrafish eggs for the experiment. The authors also thank Patricia Diogo, Carmen Barrios, Helena Teixeira and Rita Colen for their assistance during microinjection and fish rearing, and thank Marianne Cluzeaud for the guidance during the analysis of molecular biology.

The present study was supported by project PTDC/CVT/ $102481 / 2008$ - 'ULTRAFISH - Ultrasound to enhance the nutritional status of eggs and yolk-feeding larvae: a novel nutritional tool to program growth potential and metabolic abilities in juvenile fish', financed by Fundação para a Ciência e Tecnologia (FCT, Portugal). F. R. and S. E. acknowledge the financial support by FCT (Portugal) through grants SFRH/BD/ 74921/2010 and SFRH/BPD/49051/2008, respectively; J. D., S. E., P. G. and S. P. benefited from travel grants in the framework of Program PESSOA-EGIDE 2011-2012.

The authors' contributions are as follows: F. R. conducted the experiment, performed all the analytical analyses, analysed all data, performed the statistical analysis, prepared the figures and wrote the manuscript; J. D. and S. P. designed the study and supervised the research; F. R. and S. E. were responsible for the metabolic trial with $\left[{ }^{14} \mathrm{C}\right]$ glucose; F. R. and S. P. performed the gene expression analysis; J. D. formulated and manufactured the diets; S. E., P. G., I. G., M. T. D., J. D. and S. P. contributed to the final content of the manuscript.

None of the authors had conflicts of interest or financial disclosures to declare.

\section{References}

1. Moon TW (2001) Glucose intolerance in teleost fish: fact or fiction? Comp Biochem Physiol B Biochem Mol Biol 129, $243-249$

2. Hemre GI, Mommsen TP \& Krogdahl A (2002) Carbohydrates in fish nutrition: effects on growth, glucose metabolism and hepatic enzymes. Aquacult Nutr 8, $175-194$ 
3. Enes P, Panserat S, Kaushik S, et al. (2009) Nutritional regulation of hepatic glucose metabolism in fish. Fish Physiol Biochem 35, 519-539.

4. Polakof S, Panserat S, Soengas JL, et al. (2012) Glucose metabolism in fish: a review. J Comp Physiol B 182, 1015-1045.

5. Mommsen TP \& Plisetskaya EM (1991) Insulin in fishes and agnathans: history structure and metabolic regulation. Rev Aquat Sci 4, 225-260.

6. Planas JV, Capilla E \& Gutiérrez J (2000) Molecular identification of a glucose transporter from fish muscle. FEBS Letters 481, 266-270.

7. Panserat S, Medale F, Blin C, et al. (2000) Hepatic glucokinase is induced by dietary carbohydrates in rainbow trout, gilthead seabream, and common carp. Am J Physiol Regul Integr Comp Physiol 278, R1164-R1170.

8. Caruso MA \& Sheridan MA (2011) New insights into the signaling system and function of insulin in fish. Gen Comp Endocrinol 173, 227-247.

9. Andoh T (2007) Amino acids are more important insulinotropins than glucose in a teleost fish, barfin flounder (Verasper moseri). Gen Comp Endocrinol 151, 308-317.

10. Navarro I, Leibush B, Moon TW, et al. (1999) Insulin, insulinlike growth factor-I (IGF-I) and glucagon: the evolution of their receptors. Comp Biochem Physiol B Biochem Mol Biol 122, $137-153$.

11. Navarro I, Rojas P, Capilla E, et al. (2002) Insights into insulin and glucagon responses in fish. Fish Physiol Biochem 27, 205-216.

12. Panserat S, Medale F, Breque J, et al. (2000) Lack of significant long-term effect of dietary carbohydrates on hepatic glucose-6-phosphatase expression in rainbow trout (Oncorbynchus mykiss). J Nutr Biochem 11, 22-29.

13. Ekmann KS, Dalsgaard J, Holm J, et al. (2013) Glycogenesis and de novo lipid synthesis from dietary starch in juvenile gilthead sea bream (Sparus aurata) quantified with stable isotopes. BrJ Nutr 109, 2135-2146.

14. Polakof S, Mommsen TP \& Soengas JL (2011) Glucosensing and glucose homeostasis: from fish to mammals. Comp Biochem Physiol B Biochem Mol Biol 160, 123-149.

15. Lucas A (1998) Programming by early nutrition: an experimental approach. J Nutr 128, 401S-406S

16. Fang L, Liang XF, Zhou Y, et al. (2014) Programming effects of high-carbohydrate feeding of larvae on adult glucose metabolism in zebrafish, Danio rerio. $\mathrm{Br} J \mathrm{Nutr}$ 111, 808-818.

17. Rocha F, Dias J, Engrola S, et al. (2014) Glucose overload in yolk has little effect on the long-term modulation of carbohydrate metabolic genes in zebrafish (Danio rerio). J Exp Biol 217, 1139-1149.

18. Hoar WS \& Randall DJ (1988) Fish Physiology Vol. 11 The Physiology of Developing Fish, Eggs, E Larvae. San Diego, CA: Academic Press.

19. Kamler E (2008) Resource allocation in yolk-feeding fish Rev Fish Biol Fisheries 18, 143-200.

20. Badeaux AI \& Shi Y (2013) Emerging roles for chromatin as a signal integration and storage platform. Nat Rev Mol Cell Biol 14, 211-224.

21. Patel MS, Srinivasan M \& Laychock SG (2009) Metabolic programming: role of nutrition in the immediate postnatal life. J Inherit Metab Dis 32, 218-228.

22. Kimmel CB, Ballard WW, Kimmel SR, et al. (1995) Stages of embryonic development of the zebrafish. Dev Dyn $\mathbf{2 0 3}$, $253-310$.

23. European Commission (2010) Directive 2010/63/EU of the European Parliament and of the Council of 22 September
2010 on the Protection of Animals Used for Scientific Purpose. Official Journal of the European Union, L 276, vol. 53.

24. Westerfield M (2000) The Zebrafish Book. A Guide for the Laboratory Use of Zebrafish (Danio rerio), 4th ed. Eugene: University of Oregon Press.

25. Rust MB, Hardy RW \& Stickney RR (1993) A new method for force-feeding larval fish. Aquaculture 116, 341-352.

26. Rønnestad I, Rojas-Garcia CR, Tonheim SK, et al. (2001) In vivo studies of digestion and nutrient assimilation in marine fish larvae. Aquaculture 201, 161-175.

27. Field HA, Kelley KA, Martell L, et al. (2009) Analysis of gastrointestinal physiology using a novel intestinal transit assay in zebrafish. Neurogastroenterol Motil 21, 304-312.

28. Aragão C, Conceição LEC, Martins D, et al. (2004) A balanced dietary amino acid profile improves amino acid retention in post-larval Senegalese sole (Solea senegalensis). Aquaculture 233, 293-304.

29. Morais S, Koven W, Rønnestad I, et al. (2005) Dietary protein/lipid ratio affects growth and amino acid and fatty acid absorption and metabolism in Senegalese sole (Solea senegalensis Kaup 1858) larvae. Aquaculture 246, 347-357.

30. Pinto W, Rodrigues V, Dinis M, et al. (2010) Can dietary aromatic amino acid supplementation be beneficial during fish metamorphosis? Aquaculture 310, 200-205.

31. Saavedra M, Conceição LEC, Helland S, et al. (2008) Effect of lysine and tyrosine supplementation in the amino acid metabolism of Diplodus sargus larvae fed rotifers. Aquaculture 284, 180-184.

32. Amaral IP \& Johnston IA (2011) Insulin-like growth factor (IGF) signalling and genome-wide transcriptional regulation in fast muscle of zebrafish following a single-satiating meal. J Exp Biol 214, 2125-2139.

33. Seiliez I, Medale F, Aguirre P, et al. (2013) Postprandial regulation of growth- and metabolism-related factors in zebrafish. Zebrafish 10, 237-248.

34. McCurley AT \& Callard GV (2008) Characterization of housekeeping genes in zebrafish: male-female differences and effects of tissue type, developmental stage and chemical treatment. BMC Mol Biol 9, 102.

35. Pfaffl MW (2001) A new mathematical model for relative quantification in real-time RT-PCR. Nucleic Acids Res 29, e45.

36. Carvalho AP, Araujo L \& Santos MM (2006) Rearing zebrafish (Danio rerio) larvae without live food: evaluation of a commercial, a practical, and a purified starter diet on larval performance. Aquac Res 37, 107-111.

37. Gatlin DM, Barrows FT, Brown P, et al. (2007) Expanding the utilization of sustainable plant products in aquafeeds: a review. Aquac Res 38, 551-579.

38. Geurden I, Aramendi M, Zambonino-Infante J, et al. (2007) Early feeding of carnivorous rainbow trout (Oncorbynchus mykiss) with a hyperglucidic diet during a short period: effect on dietary glucose utilization in juveniles. Am J Physiol Regul Integr Comp Physiol 292, 2275-2283.

39. Vagner M, Robin JH, Zambonino-Infante JL, et al. (2009) Ontogenic effects of early feeding of sea bass (Dicentrarchus labrax) larvae with a range of dietary n-3 highly unsaturated fatty acid levels on the functioning of polyunsaturated fatty acid desaturation pathways. Br J Nutr 101, 1452-1462.

40. Srinivasan M \& Patel MS (2008) Metabolic programming in the immediate postnatal period. Trends Endocrinol Metab 19, 146-152.

41. Hanley B, Dijane J, Fewtrell M, et al. (2010) Metabolic imprinting, programming and epigenetics - a review of 
present priorities and future opportunities. Br J Nutr 104, Suppl. 1, S1-25.

42. Soanes KH, Achenbach JC, Burton IW, et al. (2011) Molecular characterization of zebrafish embryogenesis via DNA microarrays and multiplatform time course metabolomics studies. J Proteome Res 10, 5102-5117.

43. Jurczyk A, Roy N, Bajwa R, et al. (2011) Dynamic glucoregulation and mammalian-like responses to metabolic and developmental disruption in zebrafish. Gen Comp Endocrinol 170, 334-345.

44. Lahnsteiner F, Urbanyi B, Horvath A, et al. (2001) Biomarkers for egg quality determination in cyprinid fish. Aquaculture 195, 331-352.

45. Eames SC, Philipson LH, Prince VE, et al. (2010) Blood sugar measurement in zebrafish reveals dynamics of glucose homeostasis. Zebrafish 7, 205-213.

46. Tao T \& Peng J (2009) Liver development in zebrafish (Danio rerio). J Genet Genomics 36, 325-334.

47. Tehrani Z \& Lin S (2011) Endocrine pancreas development in zebrafish. Cell Cycle 10, 3466-3472.

48. Saint-Amant L \& Drapeau P (1998) Time course of the development of motor behaviors in the zebrafish embryo. J Neurobiol 37, 622-632.

49. Papasani MR, Robison BD, Hardy RW, et al. (2006) Early developmental expression of two insulins in zebrafish (Danio rerio). Physiol Genomics 27, 79-85.

50. Lillycrop KA \& Burdge GC (2012) Epigenetic mechanisms linking early nutrition to long term health. Best Pract Res Clin Endocrinol Metab 26, 667-676.

51. Robison BD, Drew RE, Murdoch GK, et al. (2008) Sexual dimorphism in hepatic gene expression and the response to dietary carbohydrate manipulation in the zebrafish (Danio rerio). Comp Biochem Physiol Part D Genomics Proteomics 3, 141-154.

52. Gomez-Requeni P, Conceicao LE, Olderbakk Jordal AE, et al. (2010) A reference growth curve for nutritional experiments in zebrafish (Danio rerio) and changes in whole body proteome during development. Fish Physiol Biochem 36, 1199-1215.

53. Spence R, Gerlach G, Lawrence C, et al. (2008) The behaviour and ecology of the zebrafish, Danio rerio. Biol Rev Camb Philos Soc 83, 13-34.

54. Burdge GC \& Lillycrop KA (2010) Nutrition, epigenetics, and developmental plasticity: implications for understanding human disease. Annu Rev Nutr 30, 315-339.

55. Yamada K \& Noguchi T (1999) Nutrient and hormonal regulation of pyruvate kinase gene expression. Biochem $J 337$, Pt 1, 1-11.

56. Panserat S (2009) Molecular regulation of intermediary metabolism focusing on utilization of dietary carbohydrates. In Molecular Research in Aquaculture, 1st ed., p. 408 [K Overturf, editor]. Ames, IA: Wiley-Blackwell, John Wiley \& Sons.
57. Panserat S \& Kaushik S (2010) Regulation of gene expression by nutritional factors in fish. Aquac Res 41, 751-762.

58. Pilkis SJ \& Granner DK (1992) Molecular physiology of the regulation of hepatic gluconeogenesis and glycolysis. Annu Rev Physiol 54, 885-909.

59. Panserat S, Plagnes-Juan E, Breque J, et al. (2001) Hepatic phosphoenolpyruvate carboxykinase gene expression is not repressed by dietary carbohydrates in rainbow trout (Oncorbynchus mykiss). J Exp Biol 204, 359-365.

60. Gonzalez-Alvarez R, Ortega-Cuellar D, Hernandez-Mendoza A, et al. (2009) The hexokinase gene family in the zebrafish: structure, expression, functional and phylogenetic analysis. Comp Biochem Physiol B Biochem Mol Biol 152, 189-195.

61. Soengas JL, Polakof S, Chen X, et al. (2006) Glucokinase and hexokinase expression and activities in rainbow trout tissues: changes with food deprivation and refeeding. $A m \mathrm{~J}$ Physiol Regul Integr Comp Physiol 291, R810-R821.

62. Panserat S, Capilla E, Gutierrez J, et al. (2001) Glucokinase is highly induced and glucose-6-phosphatase poorly repressed in liver of rainbow trout (Oncorbynchus mykiss) by a single meal with glucose. Comp Biochem Physiol B Biochem Mol Biol 128, 275-283.

63. Panserat S, Fontagne S, Bergot P, et al. (2001) Ontogenesis of hexokinase I and hexokinase IV (glucokinase) gene expressions in common carp (Cyprinus carpio) related to diet. Br J Nutr 85, 649-651.

64. Kamalam BS, Medale F, Kaushik S, et al. (2012) Regulation of metabolism by dietary carbohydrates in two lines of rainbow trout divergently selected for muscle fat content. J Exp Biol 215, 2567-2578.

65. Caseras A, Meton I, Vives C, et al. (2002) Nutritional regulation of glucose-6-phosphatase gene expression in liver of the gilthead sea bream (Sparus aurata). BrJ Nutr 88, 607-614.

66. Panserat S, Plagnes-Juan E \& Kaushik S (2002) Gluconeogenic enzyme gene expression is decreased by dietary carbohydrates in common carp (Cyprinus carpio) and gilthead seabream (Sparus aurata). Biochim Biophys Acta 1579, 35-42.

67. Canani RB, Di Costanzo M, Leone L, et al. (2011) Epigenetic mechanisms elicited by nutrition in early life. Nutr Res Rev 24, 198-205.

68. Shimeno S, Kheyyali D \& Shikata T (1995) Metabolic response to dietary carbohydrate to protein ratios in Carp. Fish Sci 61, 277-281.

69. Lin H, Romsos DR, Tack PI, et al. (1977) Effects of fasting and feeding various diets on hepatic lipogenic enzyme activities in coho salmon (Oncorbynchus kisutch (Walbaum)). J Nutr 107, 1477-1483.

70. Armstrong JL, Bonavaud SM, Toole BJ, et al. (2001) Regulation of glycogen synthesis by amino acids in cultured human muscle cells. J Biol Chem 276, 952-956. 